\title{
COMPOSIÇÃO E ATIVIDADE ANTIBACTERIANA DOS ÓLEOS ESSENCIAIS DE Senecio crassiflorus var. crassiflorus
}

Anelise Levay Murari, Fernanda Hernandes de Carvalho e Berta Maria Heinzmann*

Departamento de Farmácia Industrial, Universidade Federal de Santa Maria, Campus Universitário, 97105-900 Santa Maria RS, Brasil

Tiago Mozzaquatro Michelot e Rosmari Hörner

Departamento de Análises Clínicas e Toxicológicas, Universidade Federal de Santa Maria, Campus Universitário, 97105-900 Santa Maria - RS, Brasil

Carlos Augusto Mallmann

Departamento de Medicina Veterinária Preventiva, Universidade Federal de Santa Maria, Campus Universitário, 97105-900

Santa Maria - RS, Brasil

Recebido em 20/4/07; aceito em 3/12/07; publicado na web em 24/7/08

\begin{abstract}
COMPOSITION AND ANTIBACTERIAL ACTIVITY OF THE ESSENTIAL OILS OF Senecio crassiflorus var. crassiflorus. The essential oils of leaves, aerial and underground stems of Senecio crassiflorus var. crassiflorus were extracted by hydrodistillation and their analyses were performed by GC/MS. Qualitative and quantitative differences have been found between the analyzed parts. The main compounds of the essentials oils of the leaves were found to be oxygenated sesquiterpenes, while the oils from the aerial and underground stems showed sesquiterpene hydrocarbons as major constituents. Furthermore, the essential oils were tested against Staphylocccus aureus, Escherichia coli, Pseudomonas aeruginosa and Bacillus cereus. The essential oil of the leaves was shown to be the most active.
\end{abstract}

Keyworks: Senecio crassiflorus var. crassiflorus; Asteraceae; essential oil composition.

\section{INTRODUÇÃO}

Senecio crassiflorus (Poir.) DC var. crassiflorus (Asteraceae) é uma erva psamófila que cresce no litoral sul do Brasil, sendo conhecida popularmente como macela-graúda, ${ }^{1}$ "boleo" ${ }^{2}$ e margarida-das-dunas. ${ }^{3}$ Para esta espécie já foi descrita a presença de sesquiterpenóides do tipo isodaucano, ${ }^{4}$ alcalóides pirrolizidínicos ${ }^{5}$ e o sesquiterpeno germacreno D. ${ }^{6}$

Várias espécies pertencentes ao gênero Senecio são utilizadas na medicina popular no combate a infecções, embora apresentem toxicidade reconhecida devido à presença de alcalóides pirrolizidínicos. ${ }^{7}$ Uma vez que apresentam uma atividade metabólica especial, os vegetais superiores são capazes de produzir substâncias antibióticas utilizadas como mecanismo de defesa contra predação por microrganismos, insetos e herbívoros. ${ }^{8}$

O presente trabalho relata a análise da composição do óleo essencial de diferentes órgãos vegetais de S. crassiflorus var. crassiflorus, bem como a avaliação de sua atividade antibacteriana.

\section{PARTE EXPERIMENTAL}

\section{Material vegetal}

Senecio crassiflorus (Poir.) DC. var. crassiflorus foi coletada em abril de 2006 em Capão da Canoa, RS. A espécie foi identificada pelo Prof. Dr. N. I. Matzenbacher, do Programa de Pós-Graduação em Botânica da UFRGS. Material testemunha encontra-se depositado no herbário do Departamento de Biologia da UFSM sob o registro $\mathrm{n}^{\circ}$ SMDB 10132.

*e-mail: berta.heinzmann@gmail.com

\section{Obtenção do óleo essencial}

A extração do óleo essencial das folhas $(4,2 \mathrm{~kg})$, caules aéreos $(1,4 \mathrm{~kg})$ e caules rizomatosos $(0,5 \mathrm{~kg})$ de $S$. crassiflorus var. crassiflorus foi realizada pelo método de hidrodestilação, utilizando o aparelho de Clevenger modificado ${ }^{9}$ por $3 \mathrm{~h}$. Os óleos essenciais tiveram os seus volumes determinados para cálculo do rendimento em relação ao material vegetal fresco $(\% \mathrm{v} / \mathrm{m})$, sendo armazenados em frascos de vidro vedados e conservados à $-18{ }^{\circ} \mathrm{C}$ até $\mathrm{o}$ momento das análises.

\section{Identificação dos constituintes dos óleos essenciais}

As análises foram realizadas por cromatografia gasosa acoplada à espectrometria de massas (CG/EM) em um sistema hifenado Agilent 6890, equipado com um detector seletivo de massas série 5973. Parâmetros de análise: split inlet 1:100; gás carreador: He (1 $\mathrm{mL} / \mathrm{min}$ ); coluna capilar de sílica fundida HP5MS (Hewlett Packard, 5\% fenilmetilsiloxano, $30 \mathrm{~m} \mathrm{x} \mathrm{0,25} \mathrm{mm,} \mathrm{espessura} \mathrm{do}$ filme: $0,25 \mu \mathrm{m}$ ); programa de análise: $40{ }^{\circ} \mathrm{C}(\mathrm{Ti})$ por $4 \mathrm{~min}, 40$ $260{ }^{\circ} \mathrm{C}, 4{ }^{\circ} \mathrm{C} / \mathrm{min}$; temperatura do injetor: $220^{\circ} \mathrm{C}$; temperatura da interface: $250^{\circ} \mathrm{C}$; energia de ionização: $70 \mathrm{eV}$; banco de dados: NIST, 1998.

Os componentes dos óleos essenciais foram identificados com base no índice de retenção (IR), determinados através da utilização de uma curva de calibração de uma série homóloga de $n$-alcanos $\left(\mathrm{C}_{8}-\mathrm{C}_{32}\right)$ injetados nas mesmas condições cromatográficas das amostras e nos modelos de fragmentação dos espectros de massas, sendo ambos comparados com dados da literatura. ${ }^{10}$

A concentração dos constituintes foi calculada através da área integral de seus respectivos picos, relacionada com a área total de 
todos os constituintes da amostra, obtida pela análise utilizando o cromatógrafo gasoso (Tabela 1).

Tabela 1. Porcentagem dos componentes do óleo essencial dos diferentes órgãos vegetais de S. crassiflorus var. crassiflorus

\begin{tabular}{lcccc}
\hline IR* & Componente & Folhas & $\begin{array}{c}\text { Caules } \\
\text { aéreos }\end{array}$ & $\begin{array}{c}\text { Caules } \\
\text { rizomatosos }\end{array}$ \\
\hline 1330 & $\delta$-elemeno & - & - & 0,20 \\
1385 & $\beta$-burbuneno & - & - & 0,90 \\
1414 & $\beta$-cariofileno & - & - & 0,70 \\
1451 & humuleno & 0,55 & 2,2 & 2,9 \\
1470 & $\gamma$-gurjuneno & - & - & 0,80 \\
1471 & alo-aromadendreno & - & 0,33 & - \\
1476 & germacreno D & 6,1 & 59 & 48 \\
1485 & $\beta$-eudesmano & - & 2,4 & 1,9 \\
1491 & biciclogermacreno & 0,24 & 0,90 & 1,1 \\
1494 & $\alpha$-muuroleno & 0,34 & - & - \\
1503 & germacreno A & - & 0,70 & 0,70 \\
1514 & $\delta$-amorfeno & 3,8 & 1,4 & 3,6 \\
1528 & $\delta$-cadineno & 0,34 & 3,4 & 4,1 \\
1533 & (Z)-cadina-1,4-dieno & - & 0,55 & 1,1 \\
1537 & NI & - & 1,2 & 1,7 \\
1554 & germacreno B & 3,0 & 22 & 24 \\
1575 & germacreno D-4-ol & 0,58 & 0,42 & - \\
1584 & óxido de cariofileno & 0,26 & - & - \\
1593 & NI & 0,65 & - & - \\
1602 & viridiflorol & 2,1 & - & - \\
1625 & 1 -epi-cubenol & 0,59 & - & - \\
1643 & $\tau$-muurolol & 25 & 1,9 & 2,0 \\
1655 & $\alpha$-cadinol & 56 & 3,6 & 5,7 \\
1692 & NI & 0,45 & - & 0,60 \\
\hline
\end{tabular}

\begin{tabular}{llll}
\hline Total identificado & 98,9 & 98,8 & 97,7
\end{tabular}

*Índice de Retenção Experimental; NI: Composto Não Identificado

\section{Avaliação da atividade antibacteriana dos óleos essenciais}

A atividade antibacteriana dos óleos essenciais foi avaliada utilizando a metodologia de microdiluição em caldo, com base no documento M7-A6 (CLSI/NCCLS) para bactérias. ${ }^{11}$

Previamente aos testes, as cepas bacterianas foram ativadas em ágar Mueller-Hinton durante $24 \mathrm{~h}$ a $35 \pm 2{ }^{\circ} \mathrm{C}$.

Após este subcultivo, procedeu-se à padronização do inóculo, que consistiu na preparação de uma suspensão bacteriana em salina, cuja turvação fosse similar ao tubo 0,5 da Escala McFarland (1 x $10^{8} \mathrm{UFC} / \mathrm{mL}$ ). A seguir, esta suspensão foi diluída a 1 x $10^{6} \mathrm{UFC} /$ $\mathrm{mL}$ em caldo Mueller-Hinton, e volumes de $100 \mu \mathrm{L}$ foram então homogeneizados nos poços de uma placa de microtitulação, com $100 \mu \mathrm{L}$ do caldo Mueller-Hinton acrescido de diferentes concentrações dos óleos essenciais, resultando num inóculo final de $5 \mathrm{x}$ $10^{5} \mathrm{UFC} / \mathrm{mL}$. As placas foram incubadas a $35 \pm 2{ }^{\circ} \mathrm{C}$ durante $24 \mathrm{~h}$.

Os óleos foram solubilizados inicialmente em álcool etílico de forma a obter-se uma solução estoque de $164 \times 10^{3} \mu \mathrm{g} / \mathrm{mL}$. As concentrações finais dos óleos no meio de cultura foram 8200; 4100; $2050 ; 1025 ; 512,5 ; 256,3 ; 128,1 ; 64,1 ; 32,0 ; 16,0 \mu \mathrm{g} / \mathrm{mL}$. Os testes foram efetuados em triplicata. Como revelador foi utilizado cloreto de 2,3,5-trifeniltetrazólio. ${ }^{12} \mathrm{O}$ controle negativo foi realizado com o caldo Mueller-Hinton. O controle positivo foi efetuado com 100 $\mu \mathrm{L}$ do caldo Mueller-Hinton acrescido de $100 \mu \mathrm{L}$ do inóculo bacteriano padronizado. $\mathrm{O}$ controle do produto consistiu em 180 $\mu \mathrm{L}$ do caldo Mueller-Hinton e $20 \mu \mathrm{L}$ da solução estoque. Foram testadas quatro cepas bacterianas catalogadas e um isolado clínico
(Tabela 2). O isolamento da cepa de Bacillus cereus foi realizado a partir de uma cultura de sangue de paciente internada no HUSM (Hospital Universitário de Santa Maria), de 25 anos de idade, do sexo feminino, com diagnóstico de endocardite bacteriana.

A concentração inibitória mínima (CIM) é definida como a menor concentração capaz de inibir completamente o crescimento microbiano, nos poços de microdiluição conforme detectado a olho nu, enquanto que a concentração bactericida mínima (CBM) é a menor concentração em que o composto é capaz de agir como bactericida. Após a leitura da CIM nos poços onde não foi observado crescimento bacteriano, realizou-se o repique para placas com ágar Mueller-Hinton. A ausência de crescimento bacteriano, após $48 \mathrm{~h}$ de incubação, determinou a CBM.

Tabela 2. Resultados das CIMs e CBMs em $\mu \mathrm{g} / \mathrm{mL}$ encontradas para os óleos essenciais procedentes das folhas, caules aéreos e caules rizomatosos de $S$. crassiflorus var. crassiflorus conforme as cepas bacterianas ensaiadas

\begin{tabular}{|c|c|c|c|c|c|c|}
\hline \multirow[t]{2}{*}{ Сера АTCC } & \multicolumn{2}{|c|}{ Folhas } & \multicolumn{2}{|c|}{$\begin{array}{l}\text { Caules } \\
\text { aéreos }\end{array}$} & \multicolumn{2}{|c|}{$\begin{array}{c}\text { Caules } \\
\text { rizomatosos }\end{array}$} \\
\hline & CIM & $\mathrm{CBM}$ & CIM & $\mathrm{CBM}$ & CIM & CBM \\
\hline $\begin{array}{l}\text { Staphylococcus } \\
\text { aureus } \\
\text { ATCC } 25923\end{array}$ & 4100 & 8200 & 8200 & $>8200$ & $>8200$ & 8200 \\
\hline $\begin{array}{l}\text { Escherichia coli } \\
\text { ATCC } 25922\end{array}$ & $>8200$ & $>8200$ & $>8200$ & $>8200$ & $>8200$ & $>8200$ \\
\hline $\begin{array}{l}\text { Pseudomonas } \\
\text { aeruginosa } \\
\text { ATCC } 27853\end{array}$ & $>8200$ & $>8200$ & $>8200$ & $>8200$ & $>8200$ & $>8200$ \\
\hline $\begin{array}{l}\text { Bacillus cereus } \\
\text { ATCC } 14579\end{array}$ & 1025 & 1025 & 2050 & 4100 & 8200 & 8200 \\
\hline $\begin{array}{l}\text { Bacillus cereus } \\
\text { isolado clínico }\end{array}$ & 2050 & $>8200$ & 4100 & $>8200$ & 8200 & 8200 \\
\hline
\end{tabular}

\section{RESULTADOS E DISCUSSÃO}

Os óleos essenciais dos três órgãos vegetais de Senecio crassiflorus var. crassiflorus divergem quanto a sua coloração, rendimento, composição e atividade antibacteriana. Enquanto que o rendimento do óleo essencial das folhas, de coloração amarelaclara levemente esverdeada, foi de $0,023 \%$, a extração dos caules aéreos forneceu um óleo de coloração amarela-clara, com rendimento aproximado de $0,033 \%$. Já no caso dos caules rizomatosos, foi obtido um óleo de coloração amarela muito clara que, devido ao baixo rendimento, não foi quantificado.

Os resultados da análise da composição química dos óleos essenciais de S. crassiflorus var. crassiflorus encontram-se na Tabela 1.

Diferenças quali e quantitativas podem ser observadas nos constituintes majoritários dos óleos essenciais das folhas, quando comparados aos óleos dos demais órgãos vegetais analisados (Tabela 1). Enquanto no óleo das folhas prevalecem os sesquiterpenóides oxigenados $\alpha$-cadinol e $\tau$-muurolol $(81,0 \%)$, nos caules áereos e rizomatosos predominam os germacrenos D e B, sesquiterpenóides não oxigenados (81 e $72 \%$, respectivamente).

Quanto à atividade antibacteriana (Tabela 2), o óleo essencial das folhas destaca-se por demonstrar atividade contra um maior número de microrganismos ensaiados ( $S$. aureus e as duas cepas de Bacillus cereus), bem como por apresentar valores de CIM e CBM menores e, portanto, mais efetivos. Esta maior atividade provavelmente esteja relacionada a grande quantidade de sesquiterpenóides oxigenados presente neste óleo essencial. Os álcoois, a exemplo 
do $\alpha$-cadinol e do $\tau$-muurolol, são compostos que apresentam atividade bactericida conhecida frente a células vegetativas, agindo como agentes desnaturantes de proteínas, solventes ou agentes desidratantes. ${ }^{13}$ Segundo Griffin et al.,${ }^{14}$ os constituintes dos óleos essenciais contendo um grupamento fenólico ou alcoólico exibem efeitos inibitórios mais pronunciados sobre o crescimento microbiano, seguidos dos aldeídos e cetonas.

A comparação da atividade antibacteriana dos óleos dos caules aéreos e rizomatosos (Tabela 2) mostra que o primeiro apresentou maior atividade contra as duas cepas de $B$. cereus ensaiadas. Os resultados indicam que os constituintes menos abundantes devem ser considerados na atividade antibacteriana destes óleos, já que seus componentes majoritários são os mesmos. Burt ${ }^{15}$ descreveu que a atividade antimicrobiana dos óleos essenciais constitui um efeito sinérgico de todos os seus constituintes, e isto deve ocorrer no caso do óleo dos caules aéreos.

A atividade antimicrobiana do germacreno D, constituinte principal do óleo dos caules aéreos e rizomatosos, já foi avaliada pelos métodos de difusão em ágar ${ }^{16}$ e microdiluição em caldo. ${ }^{17,18}$ Este composto apresentou-se inativo em concentrações de até $5000 \mu \mathrm{g} /$ $\mathrm{mL}$ frente a diferentes microrganismos, entre eles Escherichia coli ATCC 25922. O mesmo pode ser evidenciado para os óleos essenciais obtidos a partir dos dois órgãos vegetais, que também foram inativos frente a esta cepa (Tabela 2). O germacreno D é um constituinte de ocorrência freqüente em espécies de Senecio, ${ }^{17}$ fato que pode ser explicado por este composto ser considerado um precursor da biossíntese de muitos outros compostos de estrutura sesquiterpenóide. ${ }^{19}$ No entanto, este constituinte não é adequado como marcador quimiotaxonômico, uma vez que, além de ser pouco abundante em várias espécies do gênero, ${ }^{20,21}$ é de ampla distribuição na natureza e é instável. ${ }^{22}$ Dados de literatura indicam que altas temperaturas, como as utilizadas na extração dos óleos essenciais por hidrodestilação, podem levar à degradação do germacreno $\mathrm{D}$ ou induzir um rearranjo molecular, originando outros compostos de natureza sesquiterpenoídica, considerados artefatos. ${ }^{23}$

O humuleno, que ocorre em maior concentração nos óleos dos caules aéreos e rizomatosos da espécie em estudo, já foi identificado no óleo essencial das folhas de $S$. grisebachii Baker. ${ }^{24}$ Para este composto, bem como para o $\alpha$-cadinol, constituinte majoritário do óleo essencial das folhas de $S$. crassiflorus var. crassiflorus a literatura relata propriedades citotóxicas. ${ }^{25,26}$

As propriedades citotóxicas detectadas para os dois compostos sugerem que estes sejam constituintes ativos dos óleos avaliados neste estudo. No entanto, o mesmo efeito citotóxico, responsável pela atividade antimicrobiana dos óleos essenciais e/ou de seus componentes, pode provocar efeitos adversos sobre o trato gastrintestinal, quando administrados em altas doses por via oral. ${ }^{27}$

A atividade dos óleos essenciais provenientes dos três órgãos vegetais frente às cepas de $B$. cereus é um fato a ser considerado, uma vez que os esporos deste bacilo Gram-positivo constituem células de resistência frente a determinados desinfetantes, anti-sépticos e aos antimicrobianos. ${ }^{28}$ Quanto ao isolado clínico de B. cereus, este mostrou-se menos suscetível ao óleo essencial das folhas e dos caules, em comparação à cepa catalogada da mesma bactéria. Estes resultados confirmam sua maior virulência e não surpreendem, uma vez que isolados clínicos freqüentemente se mostram resistentes inclusive aos antimicrobianos de utilização terapêutica. ${ }^{29}$

Concentrações inibitórias mínimas de aproximadamente 8000 $\mu \mathrm{g} / \mathrm{mL}$ para $S$. aureus já foram evidenciadas para o óleo essencial das folhas de $S$. graveolens Weed. ${ }^{30}$ Entretanto, a CBM foi muito superior à encontrada neste estudo para o óleo essencial das folhas $S$. crassiflorus, o que sugere que este possui ação bacteriostática e bactericida.
As bactérias Gram-negativas E. coli e P. aeruginosa, ao contrário das bactérias Gram-positivas utilizadas nos testes, foram resistentes às concentrações dos três óleos testados. Estes resultados concordam com os existentes na literatura, os quais relatam uma maior suscetibilidade das bactérias Gram-positivas frente aos extratos vegetais. ${ }^{15}$ Segundo Holley e Patel, ${ }^{31}$ a membrana dual apresentada pelas bactérias Gram-negativas forma um envelope complexo, protegendo-as contra a ação de agentes antimicrobianos. Uma vez que a característica comum dos compostos voláteis de plantas é sua natureza hidrofóbica, não surpreende que estudos direcionados à elucidação de seu mecanismo de ação antimicrobiana geralmente indiquem a membrana celular como primeiro alvo. ${ }^{32}$

O mecanismo de ação dos compostos terpênicos não está totalmente elucidado. Alguns estudos indicam que a atividade antibacteriana pode ser conferida pela lipofilia dos hidrocarbonetos de estrutura terpênica, que permite sua partição nos lípidios da membrana celular, aumentado sua permeabilidade e desestabilizando a estrutura da célula bacteriana. ${ }^{33}$ Esta propriedade poderia facilitar a penetração de agentes antimicrobianos convencionais no interior da célula, aumentando assim sua atividade..$^{34}$ No entanto, estudos realizados por Griffin et al. ${ }^{14}$ indicam que a baixa solubilidade dos hidrocarbonetos sesquiterpênicos em água estaria relacionada a sua baixa atividade antimicrobiana, enquanto que os sesquiterpenóides oxigenados apresentariam uma maior atividade, explicada pela capacidade de formar pontes de hidrogênio. Por outro lado, o efeito de alguns terpenóides sobre a captação de oxigênio e a fosforilação oxidativa da célula bacteriana também podem concorrer para sua atividade.

\section{CONCLUSÕES}

A composição do óleo essencial de Senecio crassiflorus var. crassiflorus variou conforme a parte do vegetal do qual este foi obtido. A variação qualitativa e quantitativa foi pequena entre os óleos obtidos dos caules aéreos e rizomatosos, sendo mais significativa quando comparada com o óleo obtido das folhas.

Os óleos essenciais obtidos dos diferentes órgãos vegetais apresentaram atividade antibacteriana diversa. A cepa de B. cereus ATCC 14579 foi a mais suscetível à ação antimicrobiana de todos os óleos, demonstrando maior sensibilidade frente ao óleo essencial das folhas. $\mathrm{O}$ óleo das folhas foi o que apresentou maior inibição frente às cepas Gram-positivas testadas. Não foi evidenciada atividade de nenhum óleo frente às cepas Gram-negativas nas concentrações testadas, o que permite aferir-lhes atividade bacteriana de estreito espectro.

\section{AGRADECIMENTOS}

Ao Prof. Dr. N. I. Matzenbacher pela localização e identificação do material vegetal. À CAPES e ao CNPq pelo apoio financeiro.

\section{REFERÊNCIAS}

1. Cabrera, A. L.; Klein, R. M. Em Flora Ilustrada Catarinense; Reitz, P. R., ed.; Herbário Barbosa Rodrigues: Itajaí, 1975.

2. Cabrera, A. L. Em A. Flora Ilustrada de Entre Ríos (Argentina), Burkart, ed..; Coleccion Científica del I. N. T. A.: Buenos Aires, 1974.

3. Cordazzo, C. V.; Seeliger, U.; Guia ilustrado da vegetação costeira no extremo sul do Brasil, FURG: Rio Grande, 1998.

4. Jares, E. A.; Pomilio, A. B.; J. High Resol. Chromat. 1989, 12, 565.

5. Trigo, J. R.; Leal, I. R.; Matzenbacher, N. I.; Lewinsohn, T. M.; Biochem. Syst. Ecol. 2003, 31, 1011.

6. Murari, A. L.; Heldwein, C. G.; Silva, G. N. S.; Santos, G. T.; Mallmann, C. A.; Heinzmann, B. H.; Resumos da $58^{a}$ Reunião Anual da Sociedade Brasileira para o Progresso da Ciência, Florianopólis, Brasil, 2006. 
7. Silva, C. M.; Bolzan, A. A.; Heinzmann, B. M.; Quim. Nova 2006, $29,1047$.

8. Gottlieb, O.; Interciência 1981, 6, 22.

9. Brasil; Farmacopéia Brasileira, $4^{\mathrm{a}}$ ed., Atheneu: São Paulo, 1988.

10. Adams, R. P.; Identification of essential oil components by gas chromatography/quadrupole mass spectroscopy, Allured Publishing Corporation: Illinois, 2001.

11. National Committee for Clinical Laboratory Standards; Methods for Dilution Antimicrobial Susceptibility Tests for bacteria that grow aerobically, Approved Standard M7-A6, 6 $6^{\text {th }}$ ed., NCCLS: Wayne, 2003.

12. Gabrielson, J.; Hart, M.; Jarelöv, A.; Kühn, I.; McKenzie, D.; Möllby, R.; J. Microbiol. Methods 2002, 50, 63.

13. Dorman, H. J. D.; Deans, S. G.; J. Appl. Microbiol. 2000, 88, 308.

14. Griffin, S. G.; Wyllie, S. G.; Markham, J. L.; Leach, D. N.; Flavour Fragr. J. 1999, 14, 322.

15. Burt, S.; Int. J. Food Microbiol. 2004, 94, 223.

16. Biavatti, M. W.; Vieira, P. C.; Silva, M. F. G. F.; Fernandes, J. B.; Albuquerque, S.; Magalhães, C. M. I.; Pagnocca, F. C.; Phytomedicine 2001, 8, 121.

17. Deuschle, R. A. N.; Dissertação de Mestrado, Universidade Federal de Santa Maria, Brasil, 2003.

18. Deuschle, R. A. N.; Camargo, T.; Alves, S. A.; Mallmann, C. A.; Heinzmann, B. M.; Rev. Bras. Farmacogn. 2007, 17, 71.

19. Bullow, N.; König, W. A.; Phytochemistry 2000, 55, 141.

20. De Feo, V.; Soria, E. U.; Soria, R. U.; Senatore, F.; Flavour Fragr. J. 2003, $18,234$.
21. Baser, K. H. C.; Demirci, B.; J. Essent. Oil Res. 2004, 16, 558.

22. De Kraker, J. -W.; Franssen, M. C. R.; De Groot, A.; König W. A.; Bouwmeester, H.; J. Plant Physiol. 1998, 117, 1381.

23. Radulovic', N.; Lazarevic', J.; Ristic', N.; Palic', R.; Biochem. Syst. Ecol. 2007, 35, 196

24. Teibler, P. G.; Rios, E.; Zeinsteger, P. A.; De Pérez, O. A.; Castellanos, M. G.; Leiva, L.; Jorge, N. L.; Vara, M. E. G.; Acta Toxicol. Argent. 2001, 9 , 86.

25. Legault, J.; Dahl, W.; Debiton, E.; Pichette, A.; Maldemont, J. C.; Planta Med. 2003, 69, 402.

26. Sylvestre, M.; Pichette, A.; Longtin, A.; Nagau, F.; Legault, J.; J. Ethnopharmacol. 2006, 103, 99.

27. Dušan, F.; Marián, S.; Katarína, D.; Dobroslava, B.; Toxicol. in Vitro 2006, 20, 1435 .

28. Drobniewski, F. A.; Clin. Microbiol. Rev. 1993, 6, 324.

29. Neely, A. N.; Holder, I. A.; Burns 1999, 25, 17.

30. Pérez, C.; Agnese, A. M.; Cabrera, J. L.; J. Ethnopharmacol. 1999, 66, 91.

31. Holley, R. A.; Patel, D.; Food Microbiol. 2005, 22, 273.

32. Stammati, A.; Bonsi, P.; Zucco, F.; Moezelaar, R.; Alakomi, H. L.; von Wright, A.; Food Chem. Toxicol. 1999, 37, 813.

33. Cowan, M. M.; Clin. Microbiol. Rev. 1999, 12, 564.

34. Brehm-Stecher, B. F.; Johnson, E.; Antimicrob. Agents Chemother. 2003, $47,3357$. 